\title{
Comparison of the environmental impact of the conventional nickel electroplating and the new nickel electroplating
}

\author{
Yasuhiko Takuma $^{1} \cdot$ Hirokazu Sugimori $^{1} \cdot$ Eri Ando $^{1} \cdot$ Kazunari Mizumoto $^{1} \cdot$ \\ Kiyotaka Tahara ${ }^{2}$
}

Received: 14 December 2016 / Accepted: 14 July 2017 /Published online: 27 July 2017

(C) The Author(s) 2017. This article is an open access publication

\begin{abstract}
Purpose To comply with the effluent regulation of boron, replacement of boric acid with citric acid in a nickel electroplating bath is proposed. Although the bath avoids the discharge of boron, it increases the discharge of nickel owing to the chelating effect of citric acid, which disturbs the wastewater treatment. To balance this trade-off, the environmental impacts of a traditional nickel plating process (the Watts bath) and the citrate bath must be compared by life cycle assessment.

Methods The life cycle impact assessment method was LIME2. To estimate the trade-off between boron and nickel discharge into wastewater, the characterization and damage factors on human toxicity and ecotoxicity were calculated. The processes were then compared using data from actual processes. The functional unit was "plating per 1-kg part." However, the plating efficiency depends on the type, shape, and surface area of the part. The data of the citrate bath were modeled. In the modeling, the amounts of nickel chloride and nickel sulfate in the citrate bath were based on the Watts bath. Results and discussion In comparison with other chemicals, the calculated characterization and damage factors of boron and nickel were found to be reasonable. The integration results revealed that the citrate bath exerted greater environmental
\end{abstract}

Responsible editor: Chris Yuan

Yasuhiko Takuma

takuma.yasuhiko@iri-tokyo.jp

1 Tokyo Metropolitan Industrial Technology Research Institute, 2-4-10, Aomi, Koto-ku, Tokyo 135-0064, Japan

2 National Institute of Advanced Industrial Science and Technology, 16-1 Onogawa, Tsukuba, Ibaraki 305-8569, Japan impact than the Watts bath. Although the Watts bath involved more environmentally damaging processes than the citrate bath, the sum of these impacts was much smaller than the impact of effluent from the citrate bath. Moreover, the environmental impact of effluent can be significantly reduced by flocculants, with almost no additional environmental impact incurred by the increased sludge.

Conclusions The newly developed citrate plating bath exerts higher environmental impact than the traditional Watts bath because the environmental impacts of the release of nickel chelated with citric acid exceed the reduced boron emissions. Therefore, there is a trade-off between the two methods. When installing the citrate bath, the wastewater treatment must be altered to reduce the nickel emissions.

Keywords LIME2 - Nickel citrate electroplating bath . Plating process $\cdot$ Trade-off $\cdot$ Watts bath $\cdot$ Wastewater treatment

\section{Introduction}

Chemical processes consume and discharge various chemicals and require large amounts of energy, with potentially adverse effects on the environment. Therefore, the environmental impact of these processes needs careful evaluation and mitigation. Among the previous studies on the evaluation and reduction of chemical effects on the environment, Kikuchi and Hirao (2010) clarified the health risks of solvent degreasing processes to workers and neighborhoods. Kikuchi et al. (2011) clarified the environmental impact trade-off between an organic solvent and aqueous cleaner in cleaning processes, and Vidal et al. (2016) clarified the environmental impacts of chemical pretreatment with chromium(VI) for electroplating acrylonitrile butadiene styrene. Erol and Thöming (2005) developed a method that optimizes the 
treatment processes of rinsing wastewater in phosphating processes; Laforest et al. (2013) developed a decision-making method for metal finishing that considers both cost and environmental impact. Recently, Teodosiu et al. (2016) evaluated the environmental impact of a water-purifying plant by three environmental impact assessment methods; life cycle assessment (LCA), environmental impact quantification (EIQ), and water footprint. Cespi et al. (2014) compared the traditional process of acrylonitrile production from propylene with alternative routes starting from propane. They assessed the sustainability of the production processes from a life cycle perspective and suggested that the LCA methodology can identify the environmental problems associated with the chemical production of a product.

Plating is a widely used industrial chemical process that offers several benefits: rust prevention, anticorrosion, heat resistance, electrical conductivity, and wear resistance. Besides these functionalities, plating can add decoration and esthetic appeal. However, the plating process releases high concentrations of metal-containing wastewater, severely affecting the environment. In Japan, industrial effluents are regulated by the Water Pollution Control Act or Sewerage Act. Since their enforcement in 2001, the national minimum effluent standards for boron and its compounds have greatly affected the plating industry. Traditionally, nickel electroplating is performed in a Watts bath (Watts 1916), which contains nickel sulfate, nickel chloride, and boric acid. To comply with the regulations, the discharged boron must be removed from the wastewater. As this is a difficult task, the provisional standard for the electroplating industry is set higher than the normal regulations. Faced with this situation, the industry has developed nickel citrate electroplating baths (citrate baths) (Doi et al. 2001), which substitutes boric acid with citric acid. Although the citrate bath avoids the discharge of boron, it increases the discharge of nickel compounds owing to the chelating effect of citric acid, which disturbs the wastewater treatment. To assess this trade-off, the environmental impacts of both plating processes must be compared by LCA.

To estimate the trade-off between the two processes, we must evaluate the environmental impacts of discharging boron and nickel compounds into water. Existing methods for life cycle impact assessments (LCIA) include Eco Scarcity (Frischknecht et al. 2009), Impact 2002+ (Jolliet et al. 2003), IMPACT world+ (Bulle et al. 2013), ReCiPe (Goedkoop et al. 2013), and LIME2 (Itsubo and Inaba 2010). However, none of these methods accommodate the impact factors of boron and nickel compounds; these factors must be calculated regardless of the applied method.

LIME2, which best reflects the situation in Japan, was selected as the LCIA method in the present study. First, the characterization and damage factors on the human toxicity and ecotoxicity of discharging boron or nickel compounds into water were calculated. Next, the environmental load and impact of the Watts and citrate baths were compared via LCA using data from actual processes, from the pretreatment process to the wastewater treatment process. A method for estimating the environmental impacts of the plating process is also discussed. In particular, by comparing monthly data, we investigated the effect of the data collection period and seasons on the results and validity of the functional unit. Finally, we identified the processes with high environmental impact and considered ways of reducing these impacts without increasing the cost of the plating process.

\section{Determining the characterization and damage factors}

\subsection{Assessment flow in LIME2}

Figure 1 presents a concept map of LIME2 and the range of objects of the assessment. In LIME2, the environmental impact is assessed by the following steps: (1) analyze the density changes in the air, water, and other environmental media after release of an environmentally damaging substance (fate analysis); (2) analyze how the density changes in the harmful substance alter the extent of exposure to human beings and other receptors in the environmental media (exposure analysis); (3) for different damage types, assess how these exposure changes alter the potential impact level of the receptor (impact analysis); (4) total the amount of damage at each common endpoint (for example, human health) (damage analysis); and (5) finally, derive an index of the integrated environmental impact by weighting the endpoints according to their importance (integration) (Itsubo and Inaba 2012).

LIME2 can handle various environmental impacts, such as global warming, mineral resource consumption, and photochemical oxidation. Here, we developed the factors of human toxicity and ecotoxicity when boron and nickel compounds contained in plating wastewater are discharged into the environment.

\subsection{Calculation of characterization factors}

Characterization assesses the potential environmental impact of a noxious compound in each impact category. The harmfulness of a chemical substance is often assessed by its exposure efficiency and its degree of toxicity. The factors that characterize human toxicity and their ecotoxicity are human toxicity potential (HTP) and ecotoxicity potential (ETP), respectively. The ETP is divided into aquatic ecotoxicity potential (AETP) for water areas and terrestrial ecotoxicity potential for land areas (Itsubo and Inaba 2012). In this study, the ecotoxicity is evaluated by the AETP because the effluent is discharged only into water. 


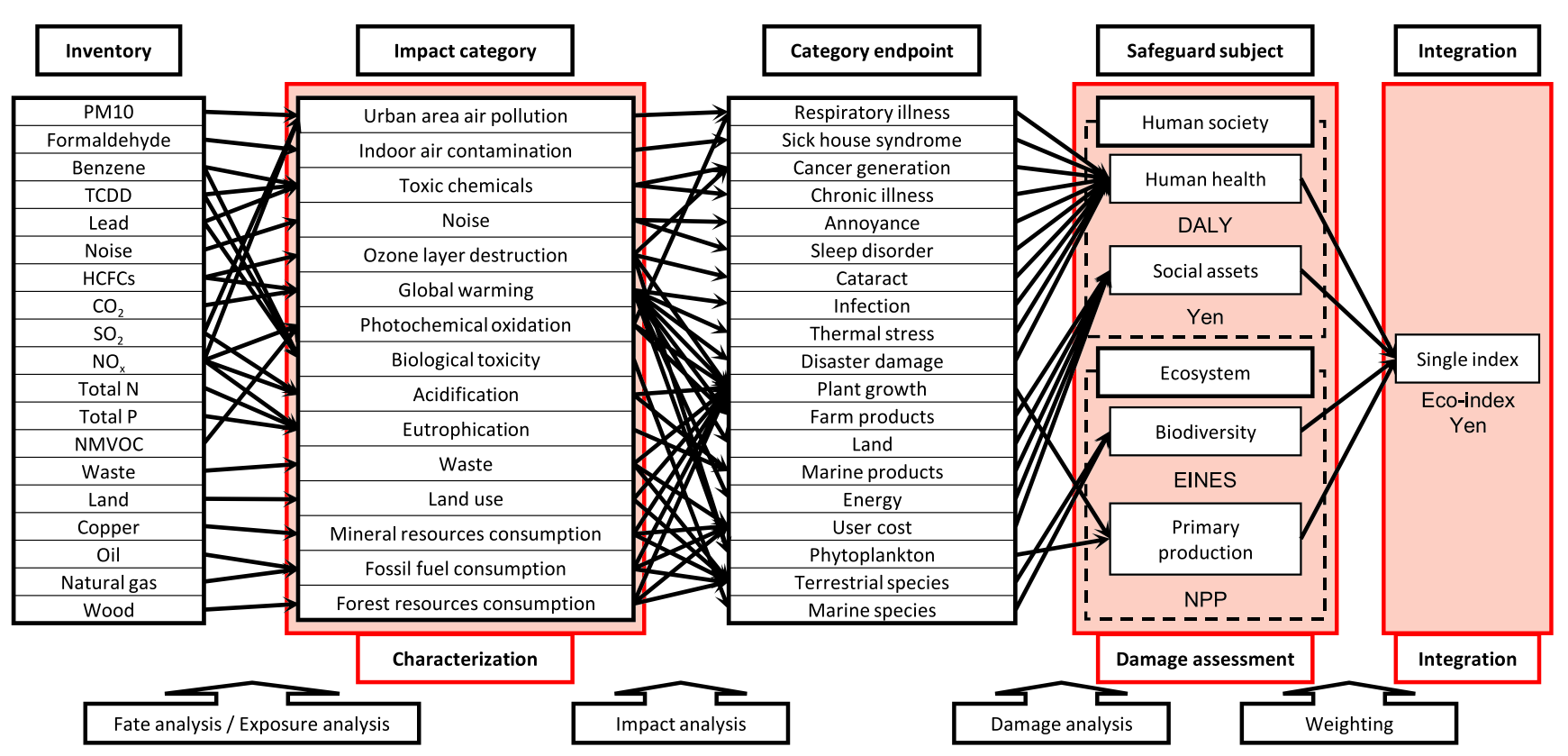

Fig. 1 Concept map of LIME2 and the range of objects of assessment

Figure 2 is a flowchart of the characterization factor calculation of toxic chemicals. The HTP is calculated from the intake amount and effect factor. First, the fate analysis of toxic chemicals in the environment was performed via the multimedia fate model. The amount of oral and inhaled intake per unit of substance emitted into a compartment was calculated as the predicted daily intake (PDI; $\mathrm{mg} / \mathrm{kg} /$ day). Next, the effect factor was computed as the reciprocal of the human limited value (HLV), defined as the maximum concentration of exposure

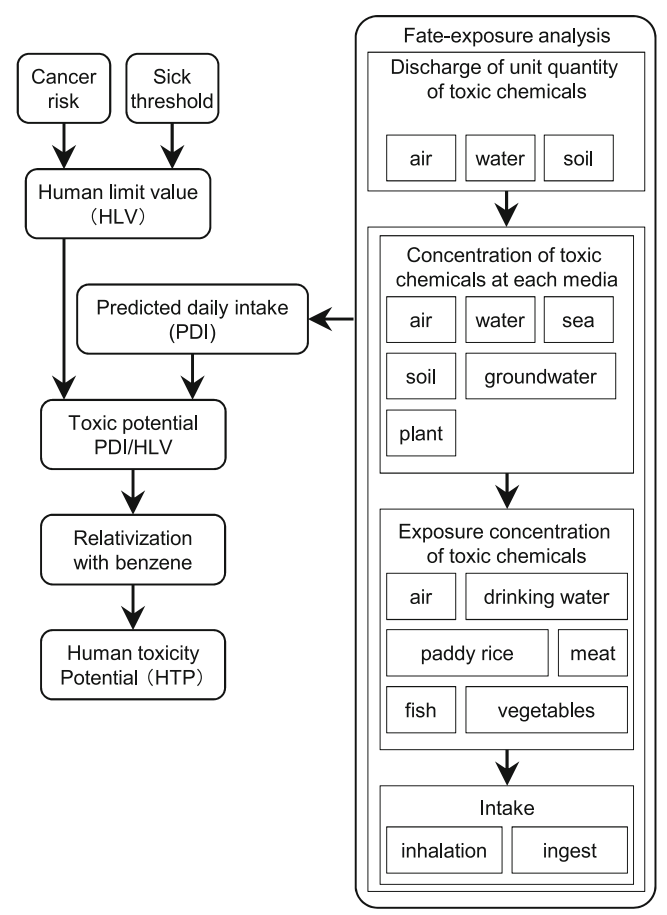

Fig. 2 Calculation of coefficient (human toxicity potential) (inhalation) or intake (oral intake) that will not affect human health. For chronic diseases, HLV is the threshold level of pathogenesis in persons exposed to a disease agent and is set to the acceptable daily intake (ADI) value calculated from the no observed adverse effect level (NOAEL). For diseases such as cancer, wherein the pathogenesis threshold is undefined, HLV is taken as the intake amount of a toxic chemical that increases the lifetime risk of carcinogenesis by $10^{-6}$ per unit. The toxicity potential is obtained by multiplying the PDI of each toxic chemical with its effect factor and summing these products. The toxicity potential is divided by the toxicity potential of a reference substance (calculated by the same procedure) to obtain the HTP. In LIME, benzene emitted into the air was chosen as the reference substance (Itsubo and Inaba 2012).

The ETP is calculated similarly to the HTP, but the PDI and ADI are replaced with the predicted environmental concentration (PEC) and predicted no-effect concentration (PNEC), respectively.

In the present study, NOAEL and other variables for calculating the characterization factors were referenced from the National Institute of Technology and Evaluation (2013a) and the Ministry of the Environment (2008) for boron and the National Institute of Technology and Evaluation (2013b) and Nakanishi and Tsunemi (2008) for nickel compounds. As nickel compounds that bypass the wastewater treatment process are water soluble, the toxicity of nickel compounds was assumed similar to the toxicity of the water-soluble nickel compounds. The fate-exposure factor, defining the efficiency from emission to exposure, is also needed in the characterization factor calculation. As the fate-exposure factors of each substance could not be calculated, we averaged the 
coefficients of arsenic and cadmium (Itsubo and Inaba 2010), which are considered to behave in a similar manner to boron and nickel compounds. The factors were calculated by the multimedia fate model developed by École Polytechnique Fédérale de Lausanne (EPFL) considering the geographical features, population, the intake amounts in different foods, and other factors pertinent to Japan.

Figure $3 \mathrm{a}, \mathrm{b}$ plots the HTP and AETP against the tolerable daily intake (TDI), respectively. Both characterization factors were correlated with the TDI of the controlled substances. The calculated coefficients of boron and nickel compounds were also correlated with TDI, confirming the reasonableness of the calculated factors.

Figure 4 compares the characterization factors calculated in this paper with those calculated by the USEtox method (Rosenbaum et al. 2008; Hauschild et al. 2008). The horizontal and vertical axes denote the midpoint characterization factor of USEtox and the characterization factor of LIME2, respectively. Both the human toxicity and ecotoxicity characterization factors of USEtox and LIME2 are correlated. However, the correlation of ecotoxicity was not as high as human health. As reasons of the difference, differences of exposure factor and effect factor between USEtox and LIME2 are conceivable. For both USEtox and LIME2, the characterization factors of human health and ecotoxicity were obtained by multiplying the fate factor, exposure factor, and effect factor. For human health, it was shown that there is a high correlation between USEtox and LIME2. Therefore, the fate factor, the exposure factor, and the effect factor are considered to be correlated between the two methods. Because the fate factor is common to human health and ecotoxicity, it can be considered that the fate factor is also correlated in ecotoxicity. Conversely, for the exposure factor, there is a difference between USEtox and LIME2. USEtox uses the concentration of dissolved chemicals as an exposure concentration of the organisms, but LIME2 uses the concentration of all chemicals. The solubility of chemicals depends on factors such as the $\mathrm{pH}$ and the presence of ions; this dependence can be the cause of the difference between USEtox and LIME2. Moreover, for the effect factor, USEtox uses the reverse of HC50, which is the geometric mean of EC50; however, LIME2 uses the reverse of PNEC. This also may cause the difference between USEtox and LIME2.

\subsection{Damage factors}

The damage factor is a measure of damage assessment. LIME defines four objects of protection: "human health," "social assets," "biodiversity," and "primary production." In this study, the category endpoints of human toxicity and ecotoxicity are chronic human disease and biodiversity of aquatic ecosystems, respectively. The damage indexes, which
Fig. 3 Comparison of calculated coefficients. a $\mathrm{HTP}_{\text {chronic. }}$ b AETP. c Human toxicity. d Ecotoxicity

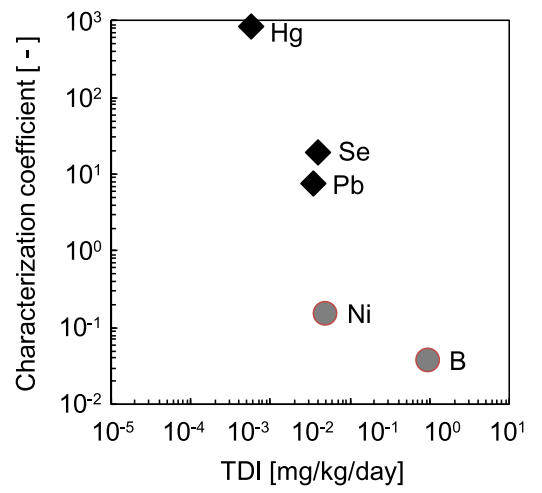

(a) HTP chronic

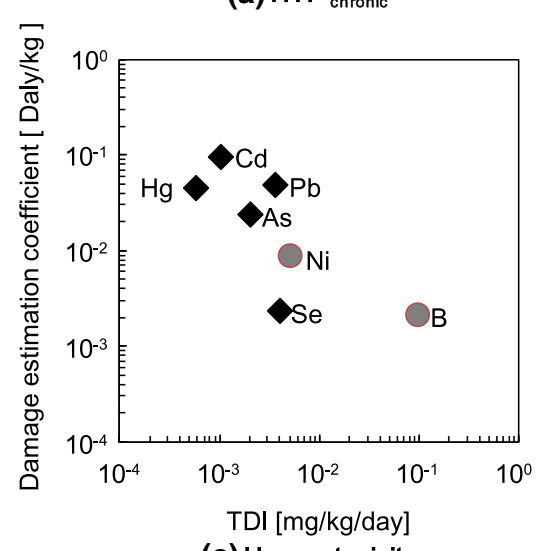

(c) Human toxicity

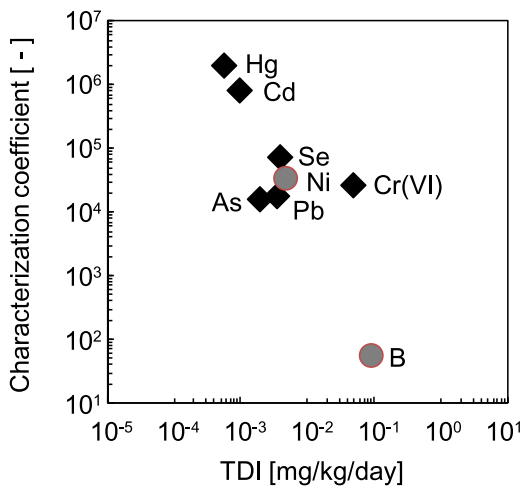

(b) AETP

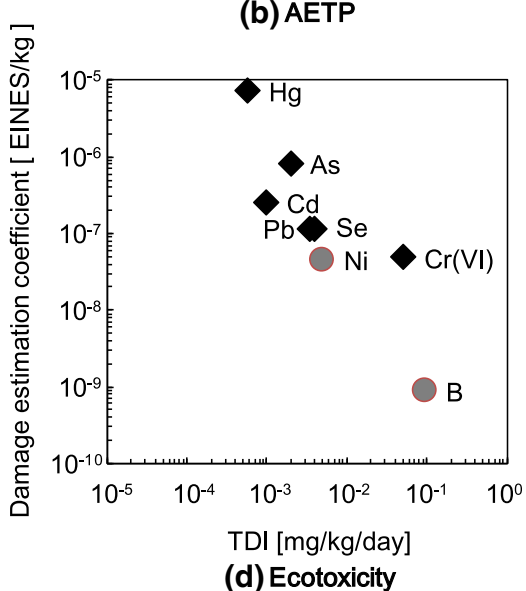


Fig. 4 Comparison of characterization factors
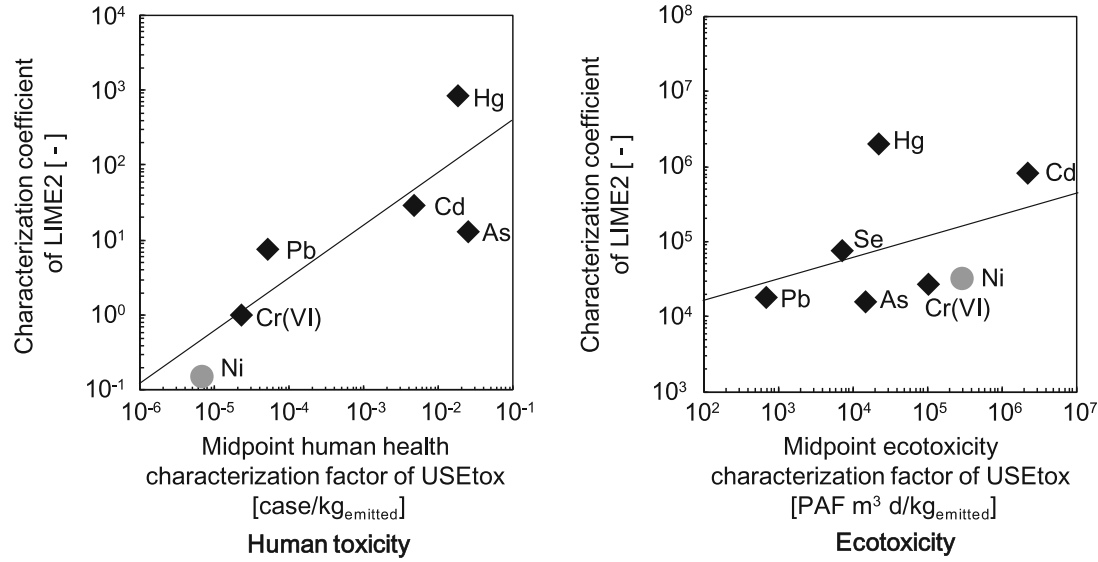

reflect the amount of damage caused by environmental changes, are the disability-adjusted life year (DALY) for human health and the expected increase in number of extinct species (EINES) measure for ecotoxicity. The DALY index is internationally used in health statistics, and EINES originates from extinction risk assessment in conversion ecology.

The damage factor was determined from the fate analysis results obtained in the characterization factor calculation. The increased risk of illness associated with the increased exposure was also analyzed. With reference to epidemiological surveys, the risk increase incurred by exposure to a unit amount of toxic chemical was expressed by the doseresponse (DR) factor, calculated as follows:

$$
\mathrm{DR}=\frac{0.1}{1.6 \times N O A E L-\text { threshold }}
$$

The damage factor of human toxicity was then calculated from the fate analysis, DR factor, DALY, and the population of Japan. The DR factor relates the amount of intake to the incidence rate. It is the slope of the linear region of the DR curve (defined as the region in which the curve can be approximated by a straight line within $10 \%$ of the incidence rate).

The damage factor of ecotoxicity is calculated as follows:

$D F_{i, \text { ecomp }}=\sum_{G} N_{G} \times F F_{i, \text { ecomp }, f c o m p} \times E F_{i, f c o m p, G}$

where $N_{G}$ is the number of species included in category $\mathrm{G}$ (such as endangered class I) among a specific group of species (such as fish or algae). $F F_{i, e c o m p, f c o m p}$ is the fate factor, defined as the amount of noxious chemical $i$ that reaches the environmental medium fcomp per unit release amount of $i$, and $E F_{i, f c o m p, G}$ is the effect factor, defining the increment in the extinction risk when a species in category $\mathrm{G}$ is exposed to a unit amount of chemical $i$ in the environmental media fcomp (Itsubo and Inaba 2012).

The NOAEL values in this calculation were those used in determining the characterization factor.
The damage factors of human toxicity and ecotoxicity are plotted against TDI in Fig. 3c, d, respectively. Both damage factors and the calculated coefficients of boron and nickel compounds were correlated with the TDIs of the controlled substances. Again, the calculated factors are apparently reasonable.

\subsection{Integration factors}

From the damage assessments, we can calculate the impacts on the four items to be protected. The derivation of a single index by weighting these four items is called integration. The weighting coefficients are given in LIME2, and the integration factor is calculated by multiplying the damage factor by its corresponding weight factor.

\section{Case study of plating process}

\subsection{Purpose of this case study}

To estimate the trade-off between the two plating processes, the impact assessment is computed from the characterization results of 13 factors: global warming, consumption of resources, acidification, waste, photochemical oxidant, eutrophication, toxic chemicals for cancer, toxic chemicals for chronic disease, ecotoxicity for aquatic creature, ecotoxicity for terrestrial creatures, energy consumption, urban area air pollution, and water consumption. The integration results in LIME2 were also evaluated.

\subsection{Outline of plating processes}

Figure 5 shows the system boundary of the plating process, in which the plating process and wastewater treatment process were evaluated in the present study. The plating process comprises the following sub-processes: (1) a pretreatment process that removes components that obstruct the plating, (2) the 


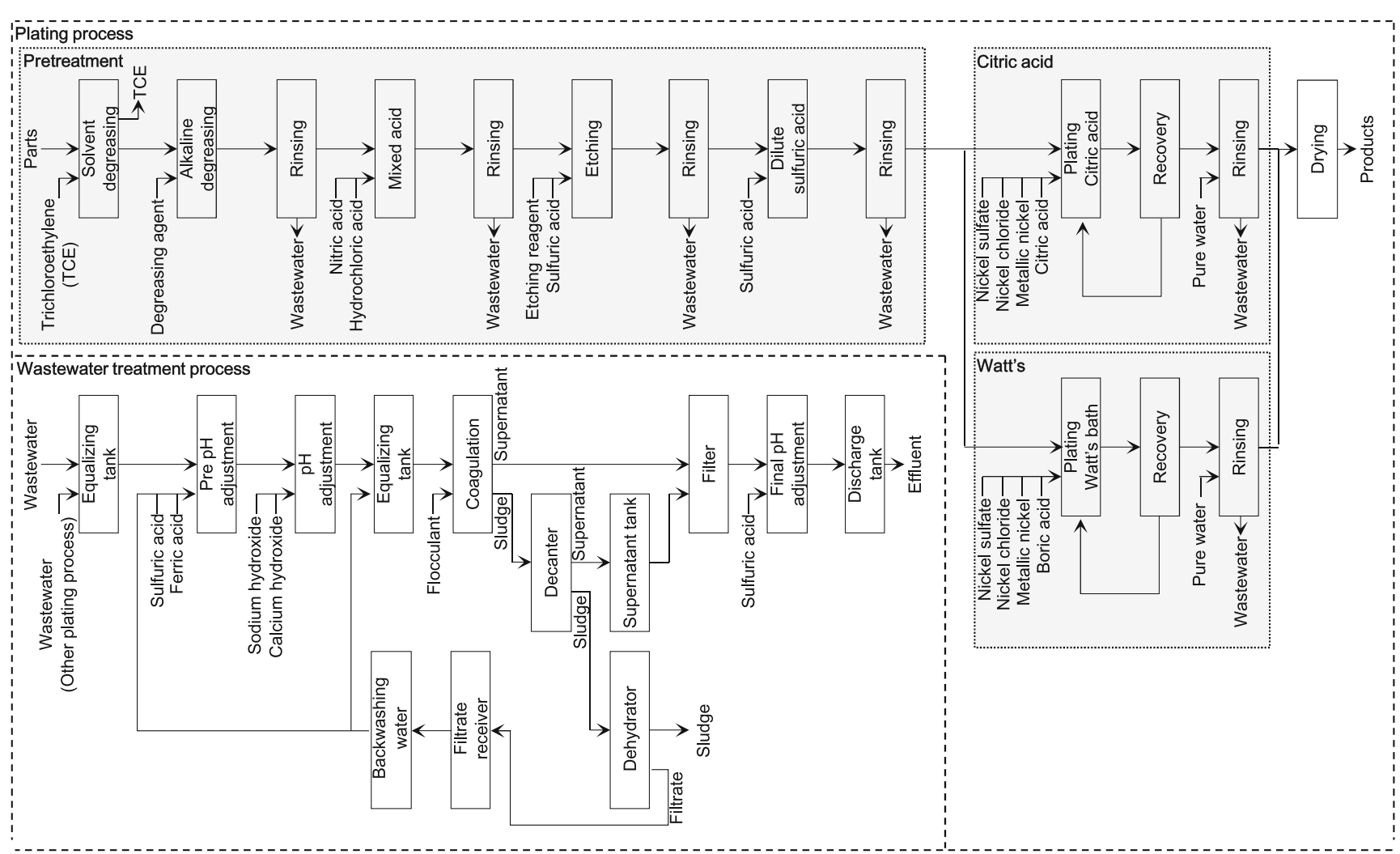

Fig. 5 Plating process and wastewater treatment process

plating of the parts, (3) a recovery process that recovers the plating solution from the products and/or jigs, and (4) a rinsing process that removes chemical contaminants from the products. The pretreatment step is subdivided into solvent degreasing, alkaline degreasing, mixed acid, etching, and dilute sulfuric acid. The pretreated parts are rinsed with tap water, but the plated parts are rinsed with purified water. The chemical contaminants in the wastewater discharged from the rinsing process are removed by the wastewater treatment process, which proceeds via pre-pH adjustment, $\mathrm{pH}$ adjustment, coagulation, dehydrator, and final $\mathrm{pH}$ adjustment. Apart from solvent degassing, the pretreatment processes of the Watts and citrate baths are identical. Moreover, the solvent degreasing and wastewater treatments are common to all plating processes in the factory.

Over time, the pretreatment and plating solutions become diluted by drag-out. When the concentrations of the chemicals in the solutions fall below the reference concentrations, they are replenished. In electroplating, the replenishment of chemicals lost by drag-out maintains the baths in immaculate condition, enabling their permanent use without replacing the solution.

In electroplating, the parts placed at the cathode receive metal dissolved from the tip of the anode. Therefore, the weights of the metal plated onto parts and the metal removed from the anode are almost identical. Consequently, the concentration of metal in the plating solution is constant and (in the absence of drag-out) requires no supplementation by metal salt. This means that the metal ions in the wastewater treatment and in the supplied metal salt have the same molecular weight.

The wastewater treatment process must remove the heavy metals that remain on the products or jigs after the recovery process. First, the heavy metals in the rinsing solution are precipitated into insoluble hydroxides by $\mathrm{pH}$ adjustment. After further $\mathrm{pH}$ adjustment, the wastewater is discharged into the sewer as effluent. Finally, the heavy-metal precipitates are collected as sludge by an industrial waste disposal contractor.

The plating fees were based on the weights of the products used in the factory. In the present study, the functional unit was the plating per $1-\mathrm{kg}$ part.

\subsection{Data collection}

Data for water, electricity, and chemical consumption were collected from February 1, 2011, to January 31, 2012. The data of March 2011 were excluded because the normal operation was disrupted by the Great Japan Earthquake. The collected data are listed in Table 1. The background data were acquired from IDEA (Japan Environmental Management Association for Industry 2011) mounted on the LCA software 
Table 1 Data collection

\begin{tabular}{|c|c|c|}
\hline Process & Item & Unit \\
\hline \multirow[t]{2}{*}{ Solvent degreasing } & Inputted trichloroethylene & $\mathrm{kg}$ \\
\hline & Emission amount of trichloroethylene (calculated from inputted and disposed TCE weight) & $\mathrm{kg}$ \\
\hline Alkaline degreasing & Inputted degreasing agent (material is sodium hydroxide) & $\mathrm{kg}$ \\
\hline \multirow[t]{2}{*}{ Mixed acid } & Inputted nitric acid & $\mathrm{kg}$ \\
\hline & Inputted hydrochloric acid & $\mathrm{kg}$ \\
\hline \multirow[t]{2}{*}{ Etching } & Inputted etchant (materials are potassium sulfate and sulfuric acid) & $\mathrm{kg}$ \\
\hline & Inputted sulfuric acid & $\mathrm{kg}$ \\
\hline Dilute sulfuric acid & Inputted sulfuric acid & $\mathrm{kg}$ \\
\hline \multirow[t]{4}{*}{ Plating (Watt's bath) } & Inputted nickel sulfate & $\mathrm{kg}$ \\
\hline & $\begin{array}{l}\text { Inputted nickel chloride (As data, raw materials were used instead of nickel chloride. The raw materials } \\
\text { were nickel oxide and hydrochloric acid.) }\end{array}$ & $\mathrm{kg}$ \\
\hline & Inputted metallic nickel & $\mathrm{kg}$ \\
\hline & Inputted boric acid & $\mathrm{kg}$ \\
\hline \multirow[t]{4}{*}{ Plating (citric acid) } & Inputted nickel sulfate & $\mathrm{kg}$ \\
\hline & $\begin{array}{l}\text { Inputted nickel chloride (As data, raw materials were used instead of nickel chloride. The raw materials } \\
\text { were nickel oxide and hydrochloric acid.) }\end{array}$ & $\mathrm{kg}$ \\
\hline & Inputted metallic nickel & $\mathrm{kg}$ \\
\hline & $\begin{array}{l}\text { Diminution of sodium citrate concentration (As data, raw materials were used instead of sodium citrate. } \\
\text { The raw materials were citric acid and sodium bicarbonate.) }\end{array}$ & $\mathrm{kg}$ \\
\hline \multirow[t]{2}{*}{ Pure water } & Inputted hydrochloric acid & $\mathrm{kg}$ \\
\hline & Inputted sodium hydroxide & $\mathrm{kg}$ \\
\hline \multirow[t]{2}{*}{ Pre $\mathrm{pH}$ adjustment } & Inputted ferric chloride & $\mathrm{kg}$ \\
\hline & Inputted sulfuric acid & $\mathrm{kg}$ \\
\hline \multirow[t]{2}{*}{$\mathrm{pH}$ adjustment } & Inputted sodium hydroxide & $\mathrm{kg}$ \\
\hline & Inputted calcium hydroxide & $\mathrm{kg}$ \\
\hline Coagulation & $\begin{array}{l}\text { Inputted flocculant (Unused in calculations because materials mainly used as flocculants have little effect } \\
\text { on result.) }\end{array}$ & $\mathrm{kg}$ \\
\hline Final $\mathrm{pH}$ adjustment & Inputted sulfuric acid & $\mathrm{kg}$ \\
\hline Sludge & Weight of sludge & $\mathrm{kg}$ \\
\hline \multirow[t]{2}{*}{ Effluent } & Discharged nickel amount (calculated from nickel concentration of effluent and volume of effluent) & $\mathrm{kg}$ \\
\hline & Discharged boric acid (= inputted boric acid at plating process) & $\mathrm{kg}$ \\
\hline $\begin{array}{l}\text { Water usage (plating process, } \\
\text { wastewater treatment) }\end{array}$ & Amount of input water & $\mathrm{m}^{3}$ \\
\hline Water usage (domestic use) & $\begin{array}{l}\text { Subtract water usage of plating process and wastewater treatment process from the water usage of the } \\
\text { entire plant }\end{array}$ & $\mathrm{m}^{3}$ \\
\hline $\begin{array}{l}\text { Electricity consumption (plating } \\
\text { process, bath heating)) }\end{array}$ & $\begin{array}{l}\text { Electricity used for heating and maintaining temperature of reagent or plating bath (calculated from bath } \\
\text { temperature, volume, material of bath wall, and room temperature) }\end{array}$ & $\mathrm{kWh}$ \\
\hline $\begin{array}{l}\text { Electricity consumption (common } \\
\text { process) }\end{array}$ & $\begin{array}{l}\text { Electricity used for lighting, air conditioning, and other maintenance processes (subtract electricity of } \\
\text { plating process and bath heating from electricity of the entire plant) }\end{array}$ & $\mathrm{kWh}$ \\
\hline
\end{tabular}

MiLCA (National Institute of Advanced Industrial Science and Technology and Japan Environmental Management Association for Industry 2011). If the corresponding data of the chemicals in a process were absent in IDEA, the raw materials were input instead. The raw materials were investigated by Kagaku-kougyou-nippousha (2010), and their amounts were calculated from the stoichiometry of the reaction from the raw materials to chemicals. That is, the estimated data were derived only from the raw materials; energy consumption and loss during manufacturing were not considered. The raw materials are shown in Table 1.

\subsection{Data treatment method}

All plating processes involve solvent degreasing, wastewater treatment, electricity consumption in common processes, and domestic water usage. Water used in the wastewater treatment process, sludge, and effluent discharged from the wastewater treatment are also commonly shared by plating processes. In addition, the pretreatment processes in Watts and citrate baths differ only by their solvent degassing processes. Acknowledging these commonalities, we allocated the inputs and outputs of these processes to the values in Table 2 . 
Table 2 Allocation methods

\begin{tabular}{ll}
\hline Item & Method \\
\hline $\begin{array}{l}\text { Solvent degreasing } \\
\text { Water (domestic use) }\end{array}$ & Allocate with weight of plated metal (all plating processes) \\
$\begin{array}{l}\text { Electricity (common process) } \\
\text { Wastewater treatment }\end{array}$ & Allocate with ratio of nickel in the sludge and ratio of \\
Water (wastewater treatment) & nickel input to each nickel plating process \\
Sludge & Nickel commensurate with moles of citric acid is discharged \\
Effluent (discharged nickel) & $\begin{array}{l}\text { without treatment. Amount of nickel is processed as discharge } \\
\text { of citric acid bath. } \\
\text { The residual nickel was allocated with amount of inputted } \\
\text { nickel salt. } \\
\text { Allocate with weight of plated metal }\end{array}$ \\
Pre and after treatment &
\end{tabular}

In this study, the functional unit was plating per 1-kg part (see Sect. 3.2). However, plated parts of the same weight differ in shape or surface area, precluding a direct comparison of plating in the Watts and citrate baths. For this reason, we modeled plating in the citrate bath, and the amount of used nickel chloride and nickel sulfate depended on the Watts bath. In this modeling, we assume that (1) the drag-out of the same parts is identical in both baths, (2) the amount of dragged-out nickel salts is proportional to the concentration of nickel salts in the bath, and (3) the surface tension of the plating solution which affects the adhesion of metal ions to the product is independent of the components and their ratios in the solution.

\section{Results}

\subsection{Results of inventory analysis}

The important results of the inventory analysis are summarized in Table 3. Data that affect the characterization results by less than $1 \%$ are excluded, and items with the same value in the Watts and citrate baths are grouped together. These items include the pretreatment process (from solvent degreasing to dilute sulfuric acid), the use of pure and standard water (plating process, domestic use), and electricity consumption (plating process, common processes).

Apart from effluent, the Watts bath scored high values in all plating and wastewater treatment processes, whereas nickel citrate electroplating bath scored highly in effluent and bath heating.

\subsection{Results of characterization}

The characterization results are shown in Fig. 6. Both plating baths incurred the same impacts on photochemical oxidation, human toxicity (carcinogenic and chronic), air pollution, and water resources. The citrate bath exerted greater impact on global warming and ecotoxicity (aquatic) than the Watts bath and consumed more energy. The Watts bath exerted higher impact in the other categories. Global warming and energy consumption were mainly affected by the electricity consumption in bath heating and by processes common to the factory; plating was mainly responsible for resource consumption, acidification, eutrophication, and terrestrial ecotoxicity; solvent degreasing mainly caused photochemical oxidation and released carcinogenic and chronic disease-causing compounds; plating and sludge were responsible for waste; effluent caused aquatic ecotoxicity; plating and electricity consumption (bath heating and common processes) polluted the urban area air; and water resources were mainly consumed by the plating process.

The human toxicities of the discharged compounds were $3.48 \times 10^{-3} \mathrm{~kg}$-benzene eq. for boron and $7.81 \times 10^{-3} \mathrm{~kg}$ benzene eq. for nickel in the Watts bath, and $1.24 \times 10^{-2} \mathrm{~kg}$ benzene eq. for nickel compounds in the citrate bath. The ecotoxicities were $4.96 \times 10^{-3} \mathrm{~kg}$-benzene eq. for boron and $1.65 \times 10^{3} \mathrm{~kg}$-benzene eq. for nickel compounds in the Watts bath, and $2.62 \times 10^{-3} \mathrm{~kg}$-benzene eq. for nickel compounds in the citrate bath. Discharged boron and discharged nickel compounds are both toxic to human health, but exert negligible toxic effect on ecosystems. To match the human toxicity and ecotoxic impacts of the discharges from the Watts bath, the nickel compounds in the effluent from the citrate bath must be reduced by 9 and $37 \%$, respectively.

\subsection{Results of damage assessment}

The damage assessment results are shown in Fig. 7. The citrate bath more adversely affects human health and biodiversity than the Watts bath, whereas the Watts bath exerts greater impact on social assets and primary production. In both processes, plating and effluent exerted the main impact on human 


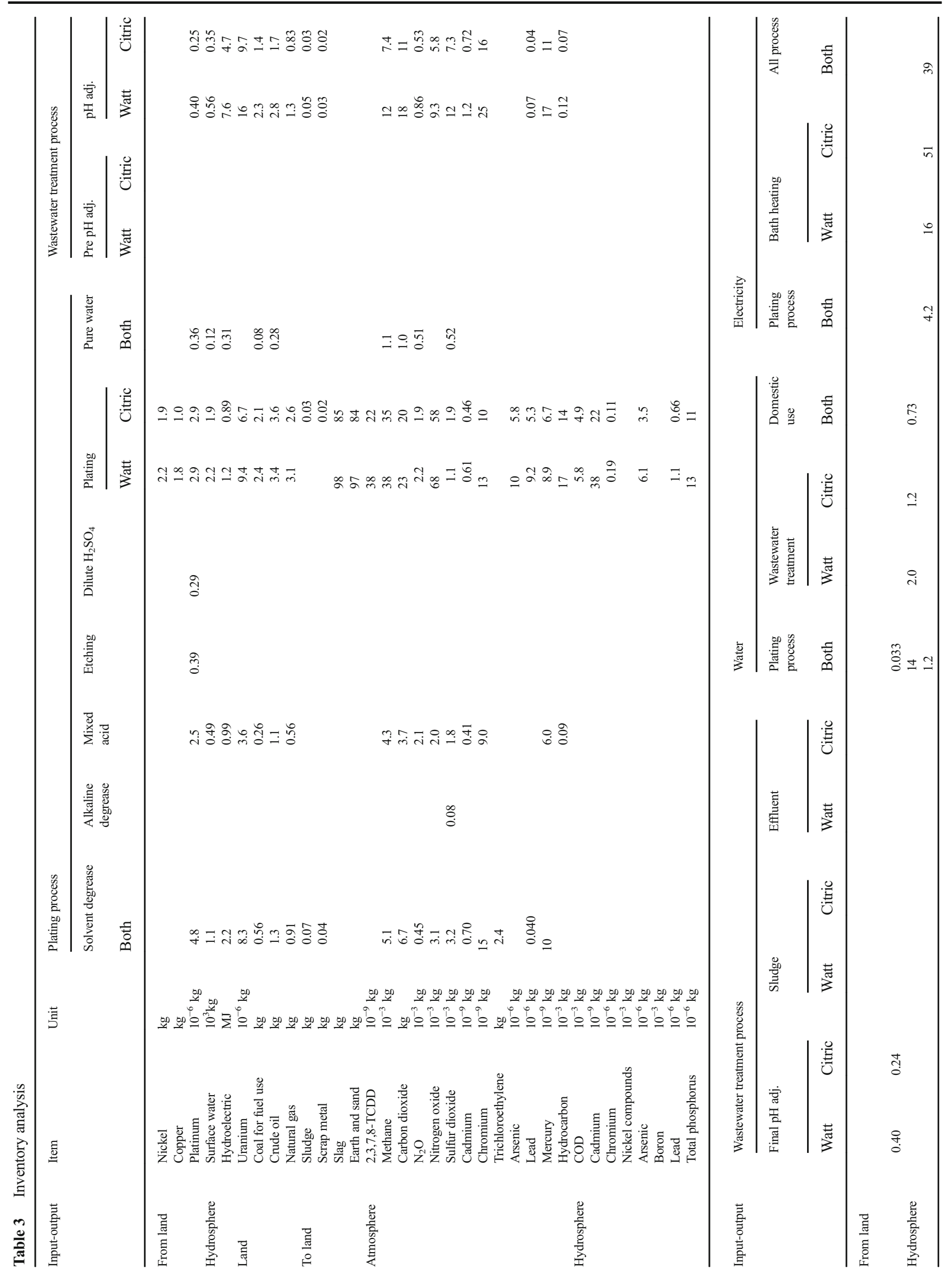




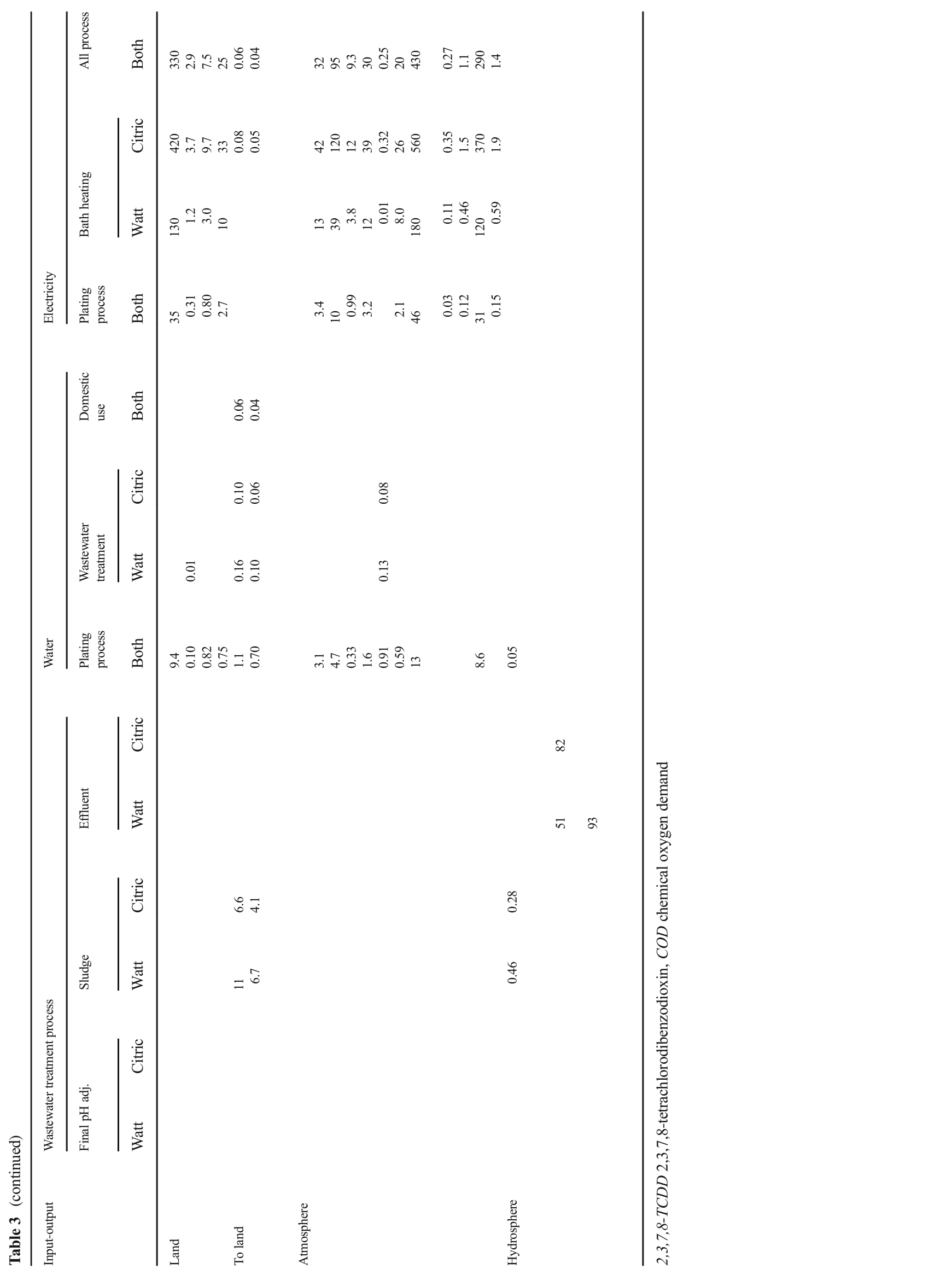



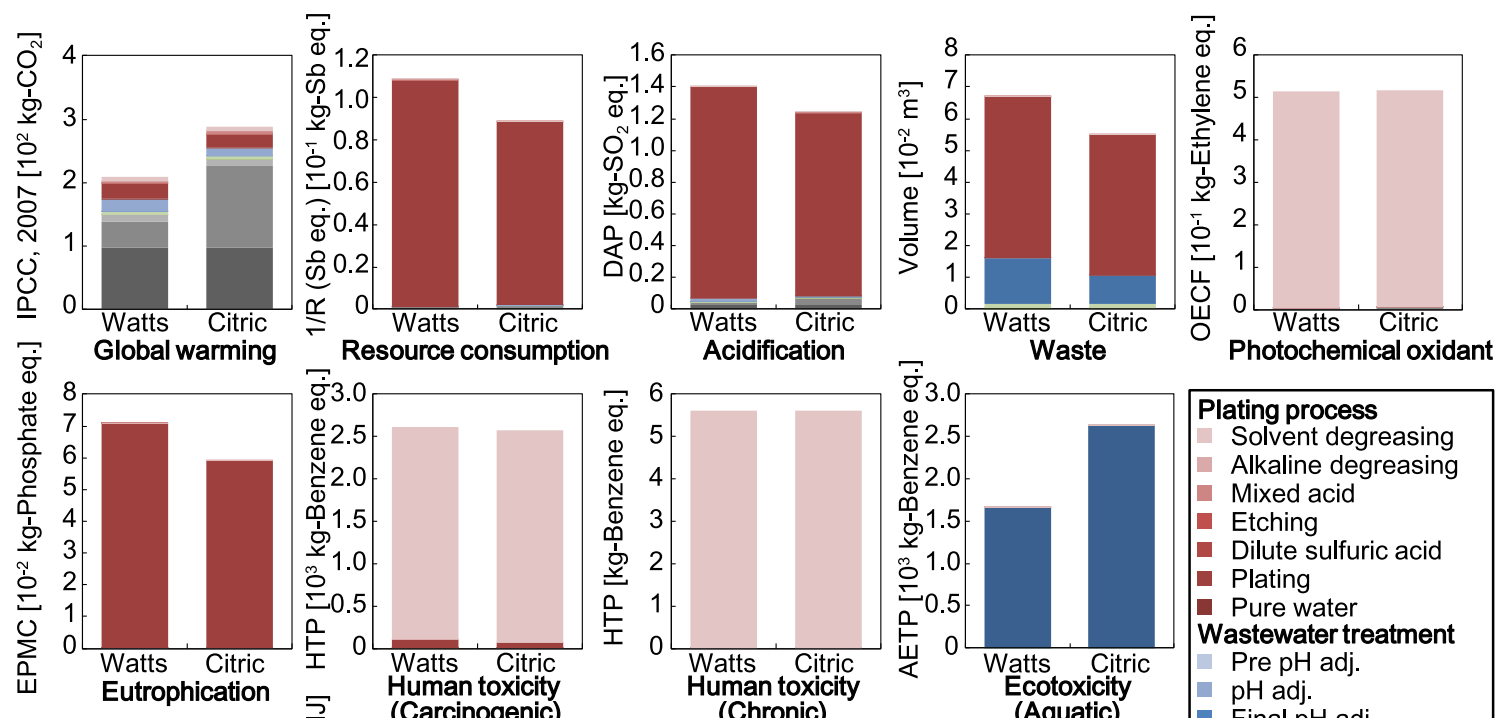

Photochemical oxidant
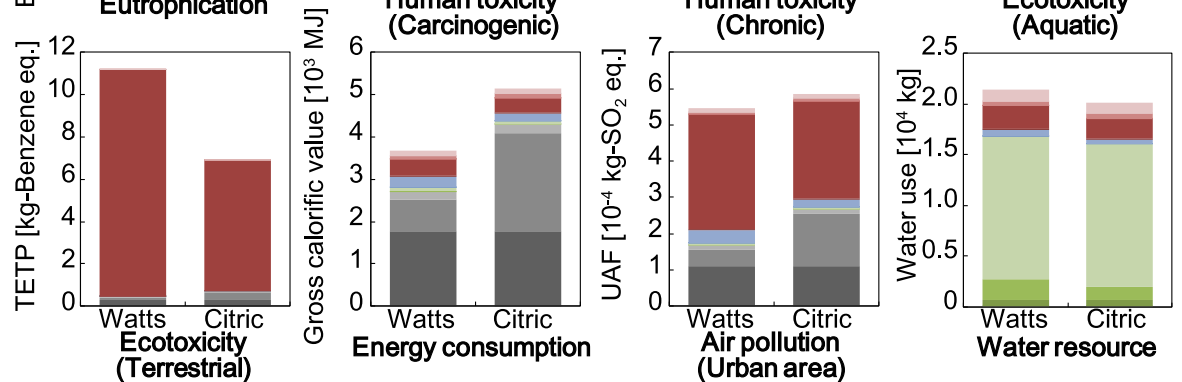

Plating process

- Solvent degreasing

- Alkaline degreasing

- Mixed acid

Etching

- Dilute sulfuric acid

- Plating

- Pure water

Wastewater treatment

Pre $\mathrm{pH}$ adj.

- pH adj.

Final $\mathrm{pH}$ adj.

- Sludge

Effluent

Plating process

- Wastewater treatment

Domestic use

Electricity

- Plating process

- Bath heating

Air pollution
Urban area)

Water resource

- All process

Fig. 6 Characterization results of the plating process

health, plating was the main affecter of social assets, solvent degreasing and plating most adversely affected primary production, and effluent exerted the main impact on biodiversity.

The human toxicities of the discharged boron and nickel compounds were $1.91 \times 10^{-4}$ [DALY] for boron and
$4.30 \times 10^{-4}$ [DALY] for nickel compounds in the Watts bath, and $6.83 \times 10^{-4}$ [DALY] for nickel compounds in the citrate bath. The biodiversity toxicities were $8.16 \times 10^{-11}$ [EINES] for boron and $2.29 \times 10^{-9}$ [EINES] for nickel compounds in the Watts bath, and $3.64 \times 10^{-9}$ [EINES] for nickel
Fig. 7 Damage assessment results of the plating process
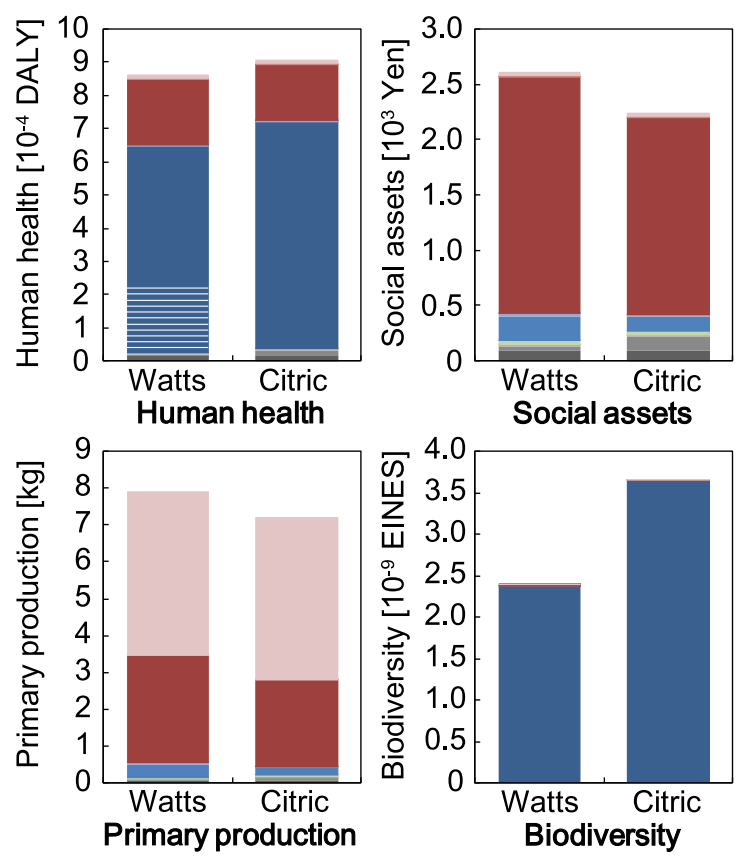

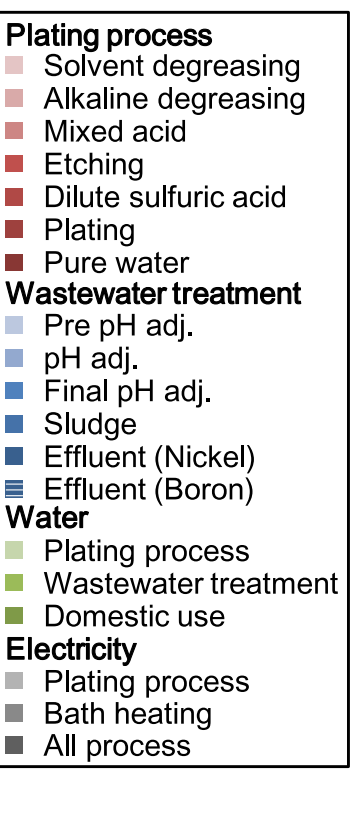


compounds in the citrate bath. These results trended similarly to the characterization results.

\subsection{Results of integration}

The integration results of each process are shown in Fig. 8a. These results were mainly affected by effluent and plating. Other significant affecters were solvent degreasing, $\mathrm{pH}$ adjustment, sludge, and the electricity consumption of bath heating and common process. Figure 8b, c shows details of "plating" and "effluent" processes in each environmental impact, respectively. Effluent was mainly responsible for ecotoxicity, followed by human toxicity. The plating process was the main contributor to urban area air pollution, waste, and resource consumption.

The integration results revealed that although the Watts bath included more individual processes with environmental impact than the nickel citrate bath, the environmental impact of the effluent from the citrate bath far exceeded the sum of the impacts from the Watts bath. Consequently, the citrate bath exerted greater environmental impact overall than the Watts bath. This means that the increased discharge of nickel compounds in the citric acid bath negates the beneficial effect of the decreased boron discharge. The human toxicities of the discharged boron and nickel compounds were $2.81 \times 10^{3}$ Yen for boron and $6.31 \times 10^{3}$ Yen for nickel compounds in the Watts bath, and $1.00 \times 10^{4}$ Yen for nickel compounds in the citrate bath. The ecotoxicities were $1.16 \times 10^{3}$ Yen for boron and $3.25 \times 10^{4}$ Yen for nickel compounds in the
Watts bath, and $5.16 \times 10^{4}$ Yen for nickel compounds in the citrate bath. According to the integration results, to match the impact of the discharges from the Watts bath, the nickel compounds in the effluent from the citrate bath must be reduced by $31 \%$.

The environmental impact of plating was higher in the Watts bath than in the citrate bath. This difference is attributed to the different concentrations of nickel compounds in the baths $(240 \mathrm{~g} / \mathrm{L}$ nickel sulfate and $55 \mathrm{~g} / \mathrm{L}$ nickel chloride in the Watts bath, versus $150 \mathrm{~g} / \mathrm{L}$ nickel sulfate and $70 \mathrm{~g} / \mathrm{L}$ nickel chloride in the citrus bath). As the total concentration of nickel compounds was higher in the Watts bath, this bath exerted higher environmental impact in the plating process. Moreover, because the wastewater treatment process is common to both baths, and the impact of the process depends on the inputted nickel compounds, the environmental impact of wastewater treatment is higher in the Watts bath than the citrate bath.

Conversely, the environmental impact of the electricity consumed in heating the plating bath was higher in the nickel citrate bath than in the Watts bath. Both baths retained the same amount of solution at the same temperature and required the same running time. However, as the product amount in the nickel citrate electroplating bath is a third of that in the Watts bath, this bath consumes electricity for temperature maintenance over a longer unused time, increasing the environmental impact per kilogram of plating. To reduce the environmental impact and cost, the citrus bath should be run only when required.

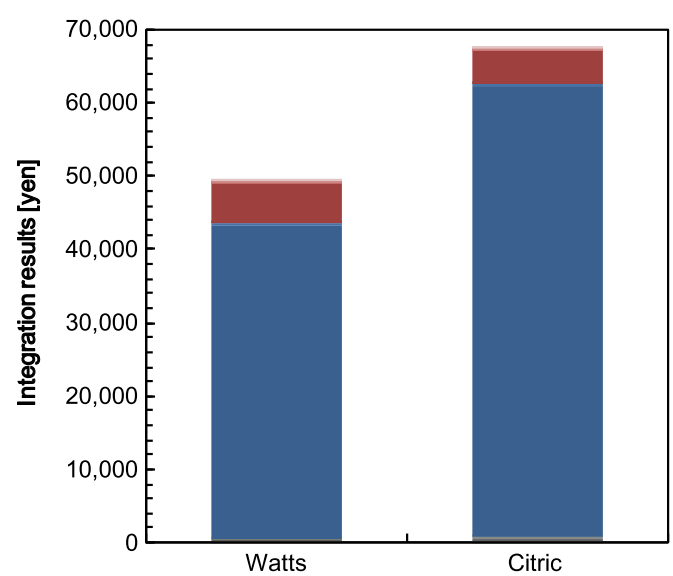

(a)All processes

\begin{tabular}{|lll|}
\hline Legend of (a) & Wastewater treatment & Water \\
\hline Plating process & Pre pH adj. & Plating process \\
Solvent degreasing & $\mathrm{pH} \mathrm{adj.}$ & Wastewater treatment \\
Alkaline degreasing & Final pH adj. & Domestic use \\
Mixed acid & Sludge & Electricity \\
Etching & Effluent & Plating process \\
Dilute sulfuric acid & & Bath heating \\
Plating & & All process \\
Pure water & & \\
\hline
\end{tabular}

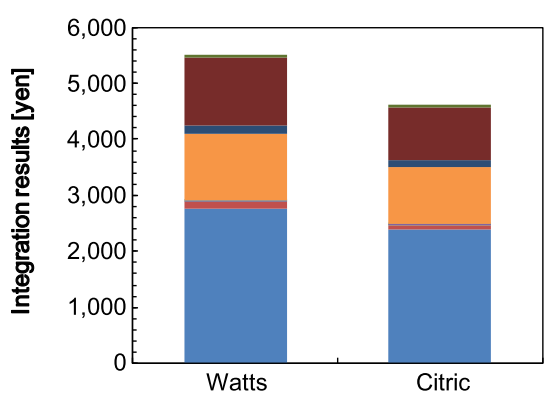

(b) Breakdown of "plating"

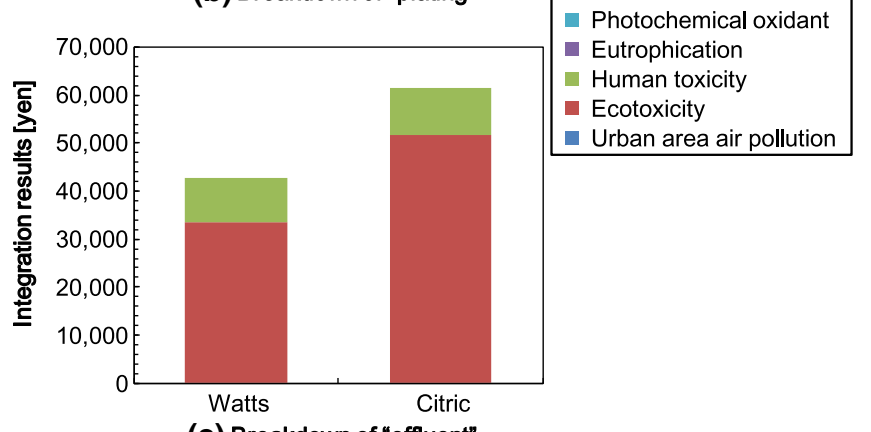

(c) Breakdown of "effluent"

Fig. 8 Integration results of the plating process. a All processes. b Breakdown of "plating." c Breakdown of "effluent" 


\section{Discussion}

\subsection{Data collection period and season}

Figure 9 shows the monthly change in the environmental impact of each process in the Watt bath, determined in the integration results. This plot reveals the seasonal and monthly fluctuations in the results. Clearly, the electroplating processes largely affect the integration results, but the effects of plating and effluent are not shown because monthly data were lacking. Only the electricity consumption of heating the plating bath showed a seasonal effect, exerting low and high environmental impact in the warm and cold seasons, respectively. This reflects the dependence of the electricity consumption of the heat radiated from the bath, which itself depends on the ambient temperature.

The results fluctuate widely from month to month. Electroplating processes yield a variety of products with various shapes and surface areas. In this study, the functional unit was plating per $1-\mathrm{kg}$ part, which ignores the complexity of the shape and surface area. Thus, the monthly fluctuations are attributed to variations in the plated products. To reduce these fluctuations, the functional unit should reflect the complexity of the shape or surface area.

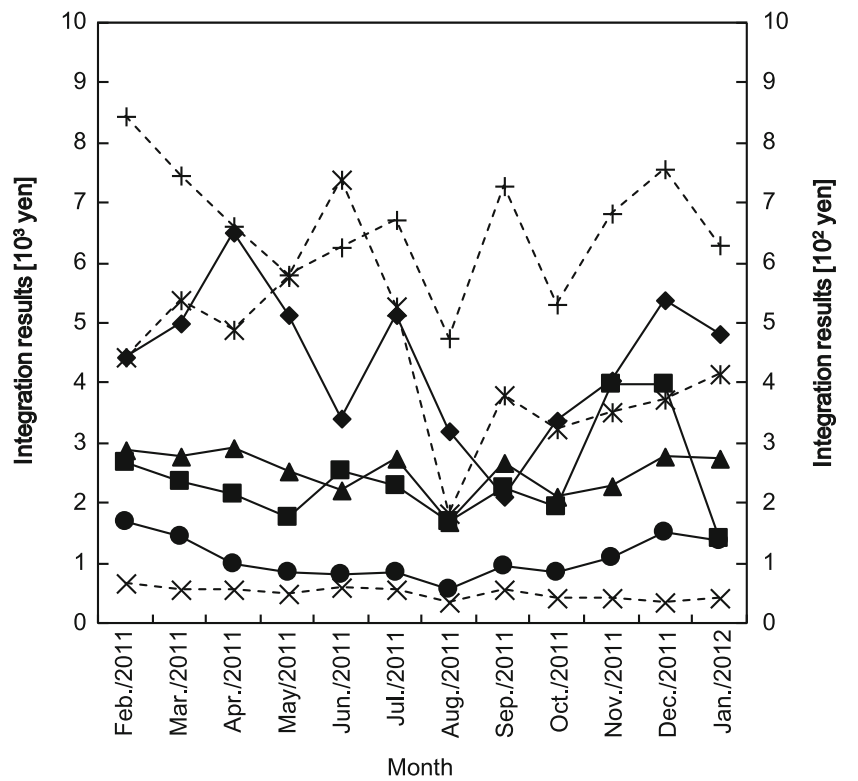

\begin{tabular}{|ll|}
\hline Left vertical axis & Right vertical axis \\
- Solvent degreasing & $---\mathrm{pH}$ adjustment \\
- Sludge & $--\times-$ Water (Wastewater treatment) \\
- Elec. (Bath heating) & -- - Water (Plating process) \\
- Elec. (Common processes) & \\
\hline
\end{tabular}

Fig. 9 The monthly change in the environmental impact of each process

\subsection{Environmentally damaging processes and reduction of environmental impact}

According to the integration results, effluent and plating exerted the greatest impact on the environment. Effluent was especially problematic. Therefore, the environmental impact of plating processes could be efficiently reduced by improving the wastewater treatment process.

To this end, we evaluated the effect of changing the wastewater treatment process on the environmental impact. The calculation assumed that (1) flocculants can absorb the chelated metal released in the wastewater, (2) this treatment will reduce the concentration of nickel compounds from $5 \mathrm{ppm}$ (the current level) to the detection limit of $64 \mathrm{ppb}$, (3) the flocculants exert negligible environmental impact, and (4) the waste increases as more nickel compounds are precipitated. Here, the detection limit was estimated from the quantification limit of nickel determined by atomic absorption spectrometry and described in JIS K 0102. The detection limit calculation is described in JIS K 0121. The increased amount of waste was estimated by calculating the sludge weight per mole of nickel from the weight and nickel content of the sludge, and multiplying this result by the amount of nickel recovered after changing the wastewater treatment.

The calculation results are shown in Fig. 10. Figure 10a shows the change in the integration results of each process by wastewater treatment improvement. Figure 10b, c shows changes in the environmental impacts of the "sludge" process that is increased by the improvement and the "effluent" process that is decreased by the improvement. It appears that adding flocculants can significantly reduce the environmental impact of plating effluent with almost no additional environmental impact of the increased sludge content. Although the assumed nickel compound concentration in effluent at $64 \mathrm{ppb}$ was selected because of its detection limit, it has the possibility that the actual concentration was low. Therefore, environmental impacts at $32 \mathrm{ppb}$ of nickel compounds, half of the detection limit, were also calculated. Based on the results, the environmental impacts were reduced by $2.4 \%$ for the Watts bath and by $3.2 \%$ for the citrate bath. From this, it was shown that if there was a slight difference in the assumed concentration, the result was not greatly affected.

As reagent input always impacts on the environment, reducing the use of chemicals will reduce the environmental impact and also the cost. Reducing the drag-out from the bath is one solution; another is reducing the concentration of the plating bath solution within the allowable range (that is, within the range that preserves the plating quality). This approach would reduce the carry-out of chemicals without reducing the drag-out. Reducing the chemical carry-out would reduce the amount of sludge in the wastewater treatment process, and is expected to largely reduce the environmental impacts of plating. 


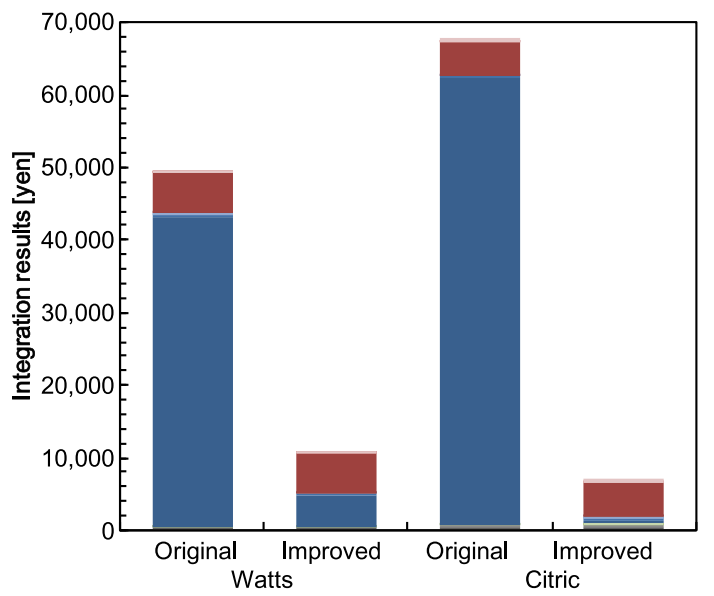

(a) All processes

\begin{tabular}{|c|c|c|}
\hline Legend of (a) & & \\
\hline Plating process & Wastewater treatment & Water \\
\hline Solvent degreasing & Pre $\mathrm{pH}$ adj. & Plating process \\
\hline Alkaline degreasing & $\mathrm{pH}$ adj. & Wastewater treatment \\
\hline Mixed acid & - Final $\mathrm{pH}$ adj. & Domestic use \\
\hline Etching & - Sludge & Electricity \\
\hline Dilute sulfuric acid & Effluent & Plating process \\
\hline - Plating & & Bath heating \\
\hline - Pure water & & All process \\
\hline
\end{tabular}

Fig. 10 Comparison of integration results before and after wastewater treatment improvement. a All processes. b Breakdown of "sludge." c Breakdown of "effluent"

Solvent degreasing was a major source of human toxicity (both carcinogenic and chronic disease) in the characterization results, but was less influential in the integration results comparing effluent and plating. The toxicity is considered to result in inhalation of the trichloroethylene used in degreasing. Consequently, this process exerted less effect on human health in the damage assessment and integration results, where the impact of inhalation was ignored in LIME2. In contrast, the characterization results included the impacts of both inhalation and oral ingestion. If the inhalation of trichloroethylene was included in the damage assessment, solvent degreasing would exert a much higher environmental impact.

\section{Conclusions}

This study evaluated the human toxicity and ecotoxicity coefficients, and the damage factors of human health and biodiversity, incurred by the ejection of boron and nickel compounds. The calculations were based on LIME2. Consistent with the coefficients of other chemicals, the calculated coefficients were correlated with the TDIs, indicating that the calculations were reasonable.

In the integration results, the recently developed nickel citrate electroplating bath exerted higher environmental impact than the traditional Watts bath. This was attributable to the increased emissions of environmentally damaging nickel compounds, which chelate with the citric acid. The effect of

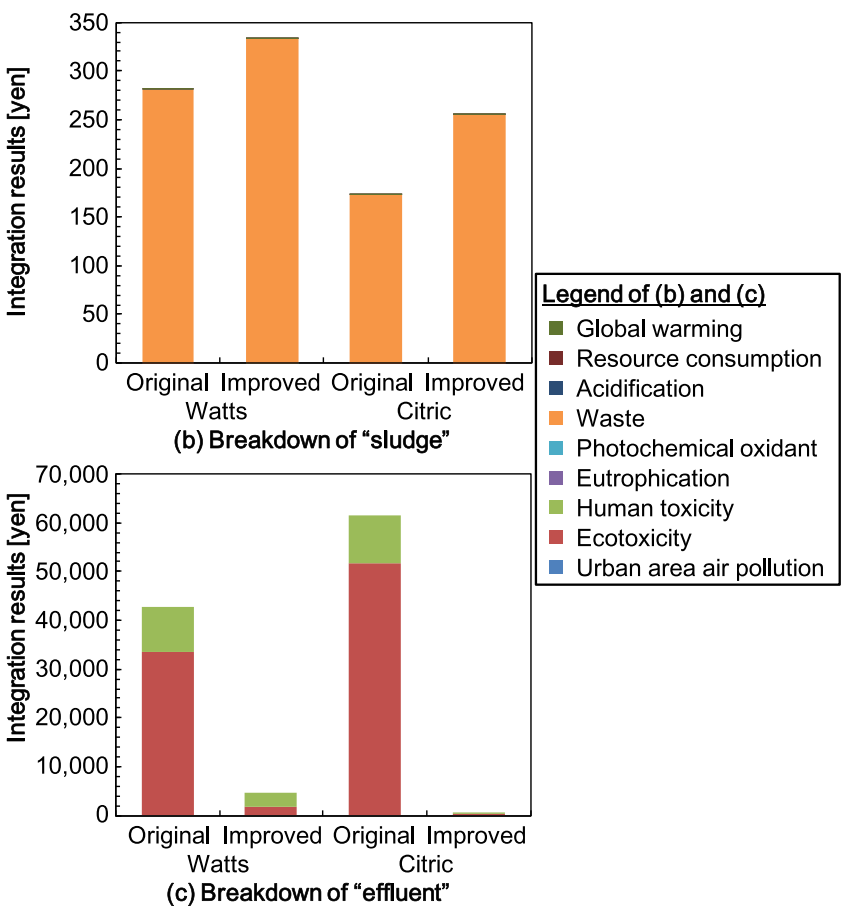

this chelation exceeds the reduction of environmental impact by reducing the boron emissions, indicating a trade-off. For this reason, when adopting the nickel citrate electroplating bath, the nickel compound emission should be adjusted to reduce by $37 \%$.

Improving the wastewater treatment process should largely mitigate the environmental impact because effluent is a major environmental impact process. The second highest environmental impact was incurred by plating, which can be reduced by reducing the drag-out. The drag-out reduction would also reduce the chemicals and load on the wastewater treatment process, benefitting cost as well as reducing environmental impact. Solvent degreasing also exerted a significant environmental impact.

From the results, an LCA method of the plating process was established. The processes exerting the greatest environmental impact were specified, and ways of mitigating their impacts were suggested.

Acknowledgements The authors would like to thank Futoshi Shiba, Hiroharu Tsuyuki, Shunpei Inukai, Yuusuke Tanno, and Atsuki Hara of Tokushu Mekki Co., Ltd. for data collection and useful comments.

Open Access This article is distributed under the terms of the Creative Commons Attribution 4.0 International License (http:// creativecommons.org/licenses/by/4.0/), which permits unrestricted use, distribution, and reproduction in any medium, provided you give appropriate credit to the original author(s) and the source, provide a link to the Creative Commons license, and indicate if changes were made. 


\section{References}

Bulle C, Margni M, Jolliet O, Rosenbaum R, Humbert S. (2013) IMPACT World+ http://www.impactworldplus.org. Accessed 17 December 2013

Cespi D, Passarini F, Neri E, Vassura I, Ciacci L, Cavani F (2014) Life cycle assessment comparison of two ways for acrylonitrile production: the SOHIO process and an alternative route using propane. $\mathrm{J}$ Clean Prod 69:17-25

Doi T, Mizumoto K, Kayashima M, Tanaka S (2001) Nickel electroplating bath using citric acid. J Surf Finish Soc Jpn 52:462-466

Erol P, Thöming J (2005) ECO-optimization of pre-treatment processes in metal finishing. Comput Chem Eng 30:587-598

Frischknecht R, Steiner R, Jungbluth N (2009) The ecological scarcity method eco-factors 2006, a method for impact assessment in LCA. Federal Office for the Environment FOEN, Bern

Goedkoop MJ, Heijungs R, Huijbregts M, De Schryver A, Struijs J, Van Zelm R (2013) ReCiPe 2008, a life cycle impact assessment method which comprises harmonized category indicators at the midpoint and the endpoint level, Fierst edition Report I: Caracterisation. http://www.lcia-recipe.net. Accessed 17 December 2013

Hauschild MZ, Huijbregts MAJ, Jolliet O, Macleod M, Margni MD, van de Meent D, Rosenbaum RK, McKone TE (2008) Building a model based on scientific consensus for life cycle impact assessment of chemicals. The search for harmony and parsimony. Environ Sci Technol 42:7032-7037

Itsubo N, Inaba A (2010) LIME2 life-cycle impact assessment method based on endpoint modeling (original title in Japanese). Japan Environmental Management Association for Industry, Tokyo

Itsubo N, Inaba A (2012) LIME2 Life-cycle impact assessment method based on endpoint modeling http://lca-forum.org/english/. Accessed 10 August 2016

Japan Environmental Management Association for Industry (2011) LCA system MiLCA ver.1.0.2

Jolliet O, Margni M, Charles R, Humbert S, Payet J, Rebitzer G, Rosenbaum R (2003) IMPACT 2002+: a new life cycle impact assessment methodology. Int J Life Cycle Assess 8:324-330

Kagaku-kogyo-nippousha (2010) 15710 of chemical products (original title in Japanese). The Chemical Daily Co, Ltd., Tokyo

Kikuchi Y, Hirao M (2010) Local risks and global impacts considering plant-specific functions and constrains: a case study of metal parts cleaning. Int J Life Cycle Assess 15:17-31
Kikuchi E, Kikuchi Y, Hirao M (2011) Analysis of risk trade-off relationships between organic solvents and aqueous agents: case study of metal cleaning processes. J Clean Prod 19:414-423

Laforest V, Raymond G, Piatyszek É (2013) Choosing cleaner and safer production practices through a multi criteria approach. J Clean Prod 47:490-503

Ministry of the Environment (2008) Profiles of the initial environmental risk assessment of chemicals Vol.6, Boron and its compounds. http:/ www.env.go.jp/chemi/report/h19-03/pdf/chpt1/1-2-3-08.pdf. Accessed 10 August 2016

Nakanishi J, Tsunemi K (2008) Risk assessment documents Vol.19 nickel. Maruzen Company, Limited, Tokyo

National Institute of Advanced Industrial Science and Technology and Japan Environmental Management Association for Industry (2011) LCI database IDEA ver.1.0.0

National Institute of Technology and Evaluation (2013a) Initial risk assessment of chemical substances, boron and its compounds http:// www.nite.go.jp/chem/chrip/chrip_search/dt/pdf/CI_02_001/risk/ pdf_hyoukasyo/304riskdoc.pdf. Accessed 10 August 2016

National Institute of Technology and Evaluation (2013b) Initial risk assessment of chemical substances, nickel compounds http://www. nite.go.jp/chem/chrip/chrip_search/dt/pdf/CI_02_001/risk/pdf hyoukasyo/232riskdoc.pdf. Accessed 10 August 2016

Rosenbaum RK, Bachmann TM, Gold LS, Huijbregts MAJ, Jolliet O, Juraske R, Koehler A, Larsen HF, MacLeod M, Margni MD, McKone TE, Payet J, Schuhmacher M, van de Meent D, Hauschild MZ (2008) USEtox - the UNEP-SETAC toxicity model: recommended characterisation factors for human toxicity and freshwater ecotoxicity in life cycle impact assessment. Int J Life Cycle Assess 13:532-546

Teodosiu C, Barjoveanu G, Sluser BR, Popa SAE, Trofin O (2016) Environmental assessment of municipal wastewater discharges: a comparative study of evaluation methods. Int J Life Cycle Assess $21: 395-411$

Vidal R, Alberola-Borràs JA, Gómez-Córdon J, Moliner E, Ortega A, Verdejo E (2016) LCA to evaluate the environmental impact for chemical pre-treatment in plastics metallization. J Polym Environ. doi:10.1007/s10924-016-0872-6

Watts OP (1916) Rapid nickel plating" transactions of the American Electrochemical Society 29:395-403 